\title{
Review of Knowledge Management in Higher Education
}

\author{
Effra Altaf Haqani ${ }^{1}$, Abd Rahman Ahlan ${ }^{2}$ \\ ${ }^{1}$ Kulliyyah of Information and Communication Technology, International Islamic University Malaysia, Department Of Information System, \\ International Islamic University Malaysia, P.O. Box 10, 50728 Kuala Lumpur, Malaysia” \\ ${ }^{2}$ Associate Professor Dr, Kulliyyah of Information and Communication Technology, International Islamic University Malaysia, Center of IT \\ advancement (CITA).International Islamic University Malaysia, P.O. Box 10, 50728 Kuala Lumpur, Malaysia
}

\begin{abstract}
Higher educational institutions (HEIs) generate and implement Knowledge amid their procedures and activities. Utilizing this Knowledge Management and innovations in higher education is as fundamental as it is in the corporate sector. If it is implemented successfully, it can prompt better decision making capacities, lessened "Product" development cycle duration (for instance, educational modules improvement and examination), enhanced scholastic and administrative Services, and diminished expenses. The objective for the paper is to emphasize and show a review of the requirement for knowledge management in higher educational institutions and to throw some light on the impact on institutions, if the knowledge that is delivered is not captured properly could lead to the phenomenon of "knowledge drain", particularly the tacit knowledge that resides in the minds of the people. This results in loss of useful knowledge from the Organization.
\end{abstract}

Keywords: Knowledge Management (KM), Higher Education (HE), Brain Drain, Collaboration, e-learning

\section{Introduction}

In present day world the achievement can be accomplished by continuously utilizing existing knowledge and making new one, because of a rapid evolving society. In this new environment, knowledge has turned into a vital asset, the most hard to exchange and with the possibility to turn into the most valuable asset.

Knowledge Management (KM) principles recognise that it is important for organisations to "know what they know.". All the Institutions immanently store, access, and convey Knowledge in some way. Knowledge is regarded as a powerful tool in today's time, future depends on those who posses knowledge and implement it. It is always easy to use the existing Knowledge rather generating the same knowledge again from time to time.(Kidwell 2000)

The management of Knowledge for an Higher Educational instate would helps in the progress of better decision making and stimulate growth in newer innovations. Hence organizations are now expected to manage their knowledge in a more effective way, in order there improve their competitiveness. $\mathrm{KM}$ is to make learning usable for more than one individual, e.g. for an association overall; that is, to share it.

In an Higher Educational Institution KM can prove to be a way to make learning usable for more than one individual, e.g. for an association overall; in the field of research or new innovations. On the other hand, Higher education foundations are stood up to with new difficulties including the effect of globalisation, internationalisation and rivalry, the different desires set on learning and research accomplishments, and the fast changes in innovations [7]

The voluminous development in the quantity of higher educational Institutions in the most recent decade has focused on the foundations with the compelling weights of rivalry and the need to perform better.
An institution wide approach to knowledge management can lead to exponential improvements in sharing knowledgeboth explicit and tacit - and the subsequent surge benefits. Higher education institutions have -significant opportunities to apply knowledge management practices to support every pan of their mission, "explains Kidwell(2001, p.24).

This prepares to perceive the critical requirement for Knowledge Management (KM) activities which is a key resource. The use of a KM methodology will empower establishments to pick up a more extensive, reflexive and integrative perspective of the institutional information for application in cross practical issues - at last prompting enhanced learning sharing and more powerful choice making, arranging and upgrade in performance. This study introduces a methodology of knowledge management in higher education and begins with a review of the writing in the field of knowledge management in higher education. Considering the key commitments in the field, a few parts of our knowledge management in higher education underscored.

\section{What is Knowledge Management?}

Epistemology is the study our strategy for of acquiring knowledge. It answers the question, "How do we know?" It encompasses the nature of concepts, the constructing of concepts, the validity of the senses, logical reasoning, as well as thoughts, ideas.

Knowledge management refers to the totality of organizational strategies aimed at creating an Organisation that is able to identify and transfer its explicit knowledge held in artefacts and tacit knowledge possessed by people and communities, and to create new knowledge. Organisations progress from basic knowledge management frameworks, for example, capturing and filtering existing information, to more mind boggling ones such giving frameworks to continuous transform the data collected into knowledge. (Leibowitz J2000 ) 


\section{International Journal of Science and Research (IJSR) \\ ISSN (Online): 2319-7064}

Index Copernicus Value (2013): 6.14 | Impact Factor (2014): 5.611

Explicit knowledge is archived data that can encourage activity. It can be communicated in formal, shared dialect. Examples incorporated are formulas, equations, rules, and best practices. Explicit knowledge is:

- Packaged

- Easily codified

- Communicable

- Transferable

Tacit knowledge is know-how and learning embedded within the minds of the general population in an association. It includes observations, bits of knowledge, encounters, and craftsmanship. Tacit knowledge is:

- Personal

- Context-specific

- Difficult to formalize

- Difficult to communicate

- More difficult to transfer (Michael Sous, Kidwell 2000)

Data are raw facts and numbers, which can be informative but by themselves provide little value for decision making, planning, or any other action. Data gain meaning once they are put into context (Kidwell, Vander Linde, and Johnson, 2000). Fig 1 shows hows a raw data is compiled \& reformed to form a useful data.

\section{Fig 1(From Raw Data to Useful Knowledge )}

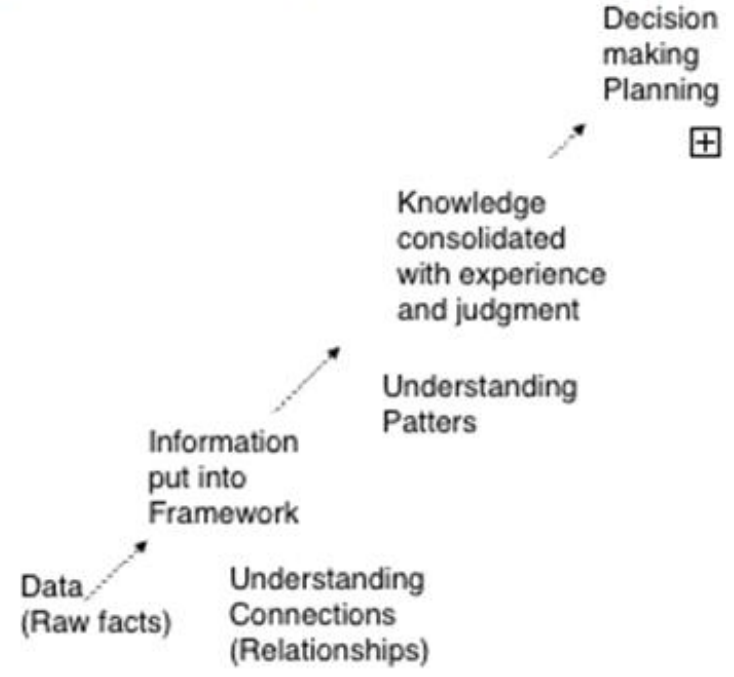

Knowledge Management has been about breaking the raw data facts into useful information. Knowledge management is involved with the exploitation and advancement of the Knowledge resources of an organisation with a perspective to facilitating the organisation's objectives. The management to be overseen incorporates both explicit, archived information, and tacit, subjective knowledge. Organisations that accomplish in Knowledge frameworks are liable to view knowledge as an boon and to progress organisational norms and value which act as a platform for the creation and sharing of knowledge" (Rowley, 2000).

\section{Knowledge management in higher education}

Education today is accountable to the strain of the marketplace. According to (Brown and Duguid, 2000) Knowledge management principles if correlated to management education will enhance the essence of academic learning process (Awad and Ghaziri, 2004)

Adopting Knowledge management techniques and technologies in higher education is as crucial as it is in the corporate world. if done conclusively, it can lead to better decisionmaking capabilities, compressed product" development cycle time (for example, curriculum development and research, revised academic and administrative services, and reduced costs. (Rowley 2000).

Higher school should have more cutting-edge technologies than companies and should enhance swiftly than them, because schools have to give the service that overwhelms them by their innovation and practical alliance. If the specialist that is prepared by this school will be not needed, higher school has to teach the graduates to manage innovations, because they will have to develop the company dynamically, improve themselves constantly, develop knowledge and skills (Ignatjeva, 2006).

All institutions store, access, and convey knowledge in an exclusive aspect; the contradicting factor is the way that value is included to the products and services they come cross by the impressive use of the knowledge capital. From Literature review it has been derived that Higher Education institutions have powerful avenues where they can practice knowledge management techniques to support their goal and to attain their vision. The benefits of the use of KM method in higher education can be grouped into five main categories, such as the assistance on the research processes, the curriculum development processes, student and alumni maintenance, organisational services, and critical planning. (Kidwell 2000)

Higher Educational Institutions have objective potential, which permits making its own arrangement of knowledge management. Saving customs, positive conservativeness, which goes together with modern management, ensure the attractiveness and market of Institutions. (Rumizen, 2004).

Higher education is gripping from the old society culture that acknowledges, What's in it for me?" to an exclusive culture that says, What's in it for our customer?" And it is adding to a society that is prepared to grasp knowledge management. (Rowling 2000)

As the organisations dispatch information management activities, they can take in lessons from their partners in the corporate segment to Capture the useful Knowledge. Some key focuses to recollect are:

1) Begin with a Methodology of receiving, transforming, consolidating knowledge and the formation of control processes;

2) Motivating and encouraging the academic community including faculty, staff, students, parents etc to share and 


\section{International Journal of Science and Research (IJSR) \\ ISSN (Online): 2319-7064}

Index Copernicus Value (2013): 6.14 | Impact Factor (2014): 5.611

grant in the Higher Learning Institution are the key for KM. [3]

3) Creating a Knowledge Repository For the institutions can Prove to be valuable ;

A Knowledge Repository is an online database that systematically captures, organises, and categorises knowledge-based information. Knowledge repositories are most often private databases that manage enterprise and proprietary information. [3]

Associating Knowledge to People: The link between knowledge and people distinguishes knowledge management systems from applications that regulate just the explicit knowledge. The most efficient user-friendly tools are failures and perform below expectation in managing information if they are not strongly associated to people and aligned with company's processes [3]

\section{Application and Benefits of KM in Higher Educational Institutions}

A knowledge management system should also sustain the flow of knowledge (including virtual teamwork) and the development of communities of practice and interests. In addition, value to knowledge may be added through collaborative effort, to improve the competitiveness of universities and provide a sustainable competitive advantage.( Rowley)

Higher education institutions play vital roles in disseminating knowledge to not just students but also staff and because they serve as knowledge providers; their main business domain falls in the knowledge category. Thus, information keeping and dissemination are important key factors in an education sector. Higher education establishments must have created suitable methodologies and arrangements to accomplish a compelling management of their knowledge.

Higher education institutions have "significant opportunities to apply knowledge management practices to support every part of their mission, " explains Kidwell et al (2001, p. 24).

Some of the Applications and Benefits that can be yielded from $\mathrm{KM}$ are:

1) Creating Repositories for Research Process:

a) Research interests within an institution or at affiliated institutions (potential subcontractors). It can benefits the institution by increased competitiveness and responsiveness for research grants, contracts, and commercial opportunities

b) Research results (where possible) and funding organizations (federal agencies, foundations, and corporations) with easy search capabilities to facilitate interdisciplinary opportunities. This can help in reduced turnaround time for research.

2) Creating a portal for research administration procedures and best practices related to:

a) Funding opportunities which can bring Facilitation of interdisciplinary research.

b) Award notification, account setup, and negotiation policies and procedures will Utilise past exploration and proposal efforts.
3) Development in Course Curriculum:

a) Repository of curriculum revision endeavours that incorporates research, effectiveness measures, best practices, lessons learned, and so forth. This will enhance quality of curriculum and programs by identifying and leveraging best practices and monitoring outcomes.

b) Portal for new faculty with guides for developing curriculum, working with senior faculty, establishing effective teaching styles, advising do's and don'ts, dealing with $\mathrm{PhD}$ students, and so forth. Implementing this application it could benefit in Enhanced responsiveness by observing and consolidating lessons learned from the experiences of partners, understudy assessments, and corporate or other constituent info. (Kidwell 2000)

According to Kidwell, Rowling and Raman Knowledge management if collaborated with Technology could prove an Important tool for enhancement of Knowledge.

Kindwell suggested that among the possible application for knowledge management, the intranet-friendly Web-based portals that integrate collaborative tools, content organised by topic, text search capabilities and so forth, are the most used. While Raman also stressed to explore how collaboration technology can be used to implement a knowledge management system for teaching and learning and for this purpose, they find in wiki technology an effective support to address knowledge management goals for teaching and learning.

Utilising joint effort innovations, a Knowledge management environment can be used for a more focused on and powerful information creation, sharing and implementing it in Higher Education. This can improve ability to access relevant knowledge when and where it is needed; and transformation of tacit knowledge into explicit knowledge'. [8] Etric Digest sugguested E-learning is one of the most important KM practices, something which one would expect higher education institutions to have as an advantage. Yet these elearning opportunities are geared most often to students as online customers, not to employees as part of capitalizing on their knowledge as an intellectual asset. The e-learning focus in $\mathrm{KM}$ is on "just-in-time knowledge, " delivered anytime and anywhere, with the traditional "course" disaggregated into "knowledge chunks

\section{Involvement of KM}

Knowledge management is known as an efficient approach for boosting the performance and productivity of organizations in this knowledge era. [18] .In present day world, the challenge faced by most KM systems is the lack of capability to systematize the capture and transfer of actionable, articulated and explicit knowledge (Delen, Al-Hawamdeh, 2009). Almost any institution in this country will make reference to the capturing of knowledge, the sharing of knowledge and the delivery of knowledge from faculty to students, " explains Stevenson. On the hand, KM includes much more, going beyond the inherent knowledge industry of colleges and Universities. Retirements, resignations and restructuring of activities leads to the phenomenon of -kowledge drain", particularly the tacit knowledge that resides in the minds of the people. This results in loss of 


\section{International Journal of Science and Research (IJSR) \\ ISSN (Online): 2319-7064}

Index Copernicus Value (2013): 6.14 | Impact Factor (2014): 5.611

useful knowledge from the organization. The challenge is to reduce knowledge loss is the ability to identify the knowledge sources and the necessary measures to ensure knowledge retention and utilization (Delen, Al-Hawamdeh, 2009). Etric Digest suggested E-learning is one of the most essential KM works on, something which one would anticipate the Higher education institutions to have benefit. Yet these e-learning opportunities are geared most often to students as online customers, not to employees as part of capitalizing on their knowledge as an intellectual asset. The e-learning stresses on KM is about"just-in-time knowledge, " delivered anytime and anywhere, with the traditional "course" disaggregated into "knowledge chunks. Making Repository of organisational Knowledge in the information storehouse as a main resource results in the accessibility of Knowledge anyplace, at anytime time. [17] A centralised advancement towards storage of organisational knowledge provides opening for collaborative work domain leading to better products and services. [7]

\section{Conclusion}

Management of Knowledge in any field is a very crucial for Organisations, and in relevance with Higher Education where Retirements, resignations and restructuring of activities leads to the phenomenon of knowledge drain", particularly the tacit knowledge that resides in the minds of the people. This results in loss of useful knowledge from the organization. (Delen, Al-Hawamdeh, 2009)

Applying Knowledge Management concepts has led Higher Education Institutions to explore how Knowledge Management might be applied in a Higher Education Institutions setting. Knowledge Management System in Higher Education Institution could boost the efficiency, effectiveness, and quality of graduates who can satisfy the employers' need in the entry level of employability in their future [K Rama Krishnan]

Using Collaboration of Technology tools with Knowledge Management it can prove to be an important factor for shaping up of storing, implementing, Capturing the relevant Knowledge for Institutions, and transformation of tacit knowledge into explicit knowledge.

The key focus of the Study is the importance of Knowledge Management for the institutions which are the building blocks of the generations ahead; knowledge drain" can bring negative effect for an organisation.

Preserving Knowledge and making use of that Knowledge by the members of Higher education can yield Crucial results for the institutions and help in preventing Knowledge drain".

\section{References}

[1] KidwellJ.J Vander Linde, M.K., Johnson, L.S. (2000), Applying Corporate Knowledge Management Practices in Higher education' EDUCAUSE QUARTER pp 2833

[2] K., Ramakrishnan, N., Mohd., Yasin (2012), Knowledge Management System and Higher Education Insti- tutions, Faculty of Computer Science and Information Technology, University of Malaya, Malaysia, International Conference on Information and Network Technology (ICINT 2012), IPCSIT vol. 37 (2012) C (2012) IACSIT Press, Singapore.

[3] International Journal Of Soft Computing And Engineering (Ijsce), Parul Sinha, Monika Arora Issn: 22312307, Volume-2, Issue-4, September 2012, and N.M Mishra. Framework for a Knowledge Management Platform in Higher Education Institution.

[4] Serban, A and Luan, J. (Eds). (2002) Knowledge Management: Building a competitive advantage in higher education: New Directions for Institutional Research, Jossey-Bass: San Francisco.

[5] Rowley, J. (2000) Is higher education ready for knowledge management?, The Iternational Journal of Educational Management, 14(7): 325-333

[6] Journal Of Theoretical And Applied Information Technology, Jayanthi Ranjan, and Saani Khalil. Application Of Knowledge Management in Management Education:A conceptual FrameWork (C) 2007 JATIT.

[7] Bhusry Mamta, and Jayanti Ranjan. "Implementing Knowledge Management in Higher Educational Institutions in India: A Conceptual Framework." International Journal of Computer Applications IJCA 29.1 (2011): $34-46$

[8] Baban, and Calin Florin. "A Knowledge Management Approach in Higher Education." JAIST Nov. 2007.

[9] Gupta, A., J., MacDaniel, J. Creating Competitive Advantage by Effectively Managing Knowledge: A Framework for Knowledge Management, Journal of Knowledge Management Practice, 3(2): 40-49, 2002

[10] Delen, D., S. Al-Hawamdeh2009 A holistic framework for knowledge discovery and management", Communications of the ACM June 2009, 52(6): 141-145.

[11] Developing a KM Culture Edition Rumizen, 2004 Book.

[12] Ignatjeva, 2006 Knowledge Management.

[13] Natalija Sedziuviene, Jolita Vveinhardt, The Paradigm of Knowledge Management in Higher Educational Institutions ISSN 1392 - 2785 (2009)

[14] Raman, M., Ryan, T., Olfman, L. Designing Knowledge Management Systems for Teaching and Learning with Wiki Technology, Journal of Information Systems Education, 16(3): 311-320, 2005.

[15] Nonaka, I., 1998, Knowledge Creating Company", Havard Business Review on Knowledge Management, Havard Business School Publishing, BostonVol. 2004, Issue 20

[16] NG EE Ling, Rosni Bakar, MD. Aminul Islam. Awareness of Knowledge Management Among Higher Learning Institutions: A Review (AENSI)

[17] Cheng, Eric C. K. "Knowledge Management for School Development." Knowledge Management for School Education SpringerBriefs in Education (2014): 11-23

[18] Nikolaus Salo"The Implications Of Knowledge Management Sustainability For Leadership In An Organization: An Exploration and Analysis of Leadership Theories and Knowledge Management Practices In Bangwita Flores, Indonesia." Journal of NTT Studies. 19 Nov. 2009 